\title{
Proceeding
}

Supplementary Issue: Autumn Conferences of Sports Science. Costa Blanca Sports Science Events, 18-19 December 2020. Alicante, Spain.

\section{Analysis of differences according to gender in the level of physical activity, motivation, psychological needs and responsibility in Primary Education}

\author{
ADRIÁN FERNÁNDEZ-HERNÁNDEZ, DAVID MANZANO-SÁNCHEZ \, JOSÉ FRANCISCO JIMÉNEZ- \\ PARRA, ALFONSO VALERO-VALENZUELA
}

Department of Physical Activity and Sport, University of Murcia, Murcia, Spain

\begin{abstract}
The objective of the study was to verify the differences according to gender in the levels of physical activity, motivation, basic psychological needs satisfaction and responsibility in students of 5th and 6th grade of Primary Education ( $M=10.51, S D=.53)$. In total, 68 students answered a series of questionnaires evaluating the intention to be physically active, motivation, the satisfaction of basic psychological needs, and the levels of personal and social responsibility. These subjects also wore an accelerometer for 1 week to objectively measure the level of Physical Activity (PA). There were 43 boys and 25 girls. Results show that boys had a higher index of PA during the week, especially at moderate intensity. Boys also had higher values of sedentary lifestyle. Significant differences were found in personal and social responsibility in favour of girls, finding no differences in the intention to be physically active. It is concluded that, girls had more adaptive values referred to responsibility. Furthermore, boys had a better adaptative values referred to PA lifestyle than girls but worse in sedentarism. It is highly recommended to objectively measure the PA levels to ensure reliable results to carry out the appropriate actions.
\end{abstract}

Keywords: Self-determination theory; Physical education; Values; Lifestyle; Sedentarism.

Cite this article as:

Fernández-Hernández, A., Manzano-Sánchez, D., Jiménez-Parra, J.F., \& Valero-Valenzuela, A. (2021). Analysis of differences according to gender in the level of physical activity, motivation, psychological needs and responsibility in Primary Education. Journal of Human Sport and Exercise, 16(2proc), S580S589. doi:https://doi.org/10.14198/jhse.2021.16.Proc2.42

Corresponding author. Department of Physical Activity and Sport, University of Murcia, Murcia, Spain. http://orcid.org/00000003-2155-4515

E-mail: david.manzano@um.es

Abstract submitted to: Autumn Conferences of Sports Science. Costa Blanca Sports Science Events, 18-19 December 2020. Alicante, Spain.

JOURNAL OF HUMAN SPORT \& EXERCISE ISSN 1988-5202

(c) Faculty of Education. University of Alicante

doi:10.14198/jhse.2021.16.Proc2.42

S580 $2021 \mid$ Proc2 | VOLUME 16

(C) 2021 University of Alicante 


\section{INTRODUCTION}

The evaluation of physical activity (PA) levels in students aged between 5 to 17 years old is one the main fields of research in sport sciences and education due to the increasingly rates of sedentarism and obesity in children in the world (Di Cesare et al., 2019). Several approaches have been made through the latest years in order to evaluate how much children move during the day and how much of an impact can cause the application of a specific PA program in the levels of students' total activity (Mura et al., 2015). Nevertheless, these interventions remain needlessly as the number of children that do not meet the recommended minimum of $60 \mathrm{~min}$ of moderate to vigorous activity is around half of the total population (Van Hecke et al., 2016; Bull et al., 2020). One of the main strategies to objectively measure PA levels in students is by using accelerometers (Mura et al., 2015) which quantify how much a person moves during a specific number of days, generally a whole week (Calahorro-Cañada et al., 2015; Cordero-Aguilar et al., 2014). Another factor to have in consideration regarding to PA is the actual predisposition or intention of children to be active. The intention is considered as the closest predictor of behaviours and reflects the relative strength of an individual to maintain that behaviour. Thus, a high predisposition to PA showed by an individual is usually related to actual PA practice in the future (Arias-Estero et al., 2013).

In order not to only measure PA levels, a much deep understanding of children's psychological and social context is required (Cheng et al., 2020). At that point is where the study of factors such as self-determined motivation, psychological needs satisfaction and personal and social responsibility could play an important role.

Self-determination theory (SDT) explains how human actions are influenced by personal and motivational factors (Deci and Ryan, 2012). This theoretical framework has been used in the Physical Education (PE) field of research under the purpose to analyse which are the connections between motivational factors and PA levels or engagement to PA in children and adolescents (Kalajas-Tilga et al., 2020). SDT is composed by three basic psychological needs: autonomy, competence and relatedness. These three dimensions project four different outcomes in terms of human motivational levels distinguishing between: intrinsic motivation, identified regulation, introjected regulation and external regulation and amotivation (Ryan and Deci, 2017).

Apart from the motivational context of students, social factors such as coexistence among young population is one of the matters of debate between various countries in Europe (Cangas et al., 2007). This coexistence is represented by personal and social responsibility (Sánchez-Alcaraz et al., 2019). PE could be used as an effective strategy to reduce violence and conflict among students (Hellison, 2011). However, sport and PE by themselves do not automatically decrease this kind of behaviours (Carranza and Mora, 2003). Changes in values and attitudes occur more easily if they are raised in a systematic way and if they have an educational orientation in the sports context itself. In this way, a PE program should be well structured so that it can constitute an effective instrument for promoting personal and social responsibility by taking advantage of the high interactivity and emotional character of the PA that allows teaching values and promote social and emotional development (Courel-lbañez et al., 2019).

Only a few studies have investigated the role of psychological needs satisfaction, motivation and social factors such as personal and social responsibility in a PE context adding the objectively measurement of PA in children or adolescents (Standage et al., 2012; Wang, 2017). Thus, the objectives of the present study were: 1) to compare the differences according to gender in the PA levels, motivation, basic psychological needs and responsibility in Primary Education students and 2) to examine if motivation, psychological needs, responsibility and predisposition to PA have correlations with PA levels. 


\section{MATERIAL AND METHODS}

\section{Design and participants}

The present study was confectioned as a cross-sectional, descriptive and correlational study with a single measurement (Montero and León, 2007) whose sample was composed by a total of 68 students (43 boys and 25 girls aged between 10 and 11 years old, $M=10.51 \mathrm{SD}=.53$ ) belonging to 4 different public schools in Spain.

\section{Instruments}

In order to evaluate SDT, PRS, intent to be physically active and PA levels a variety of instrument was implemented:

1. Motivation was measure through the questionnaire: School Motivation Scale (SMS) (Núñez-Alonso et al., 2005). The instrument is made up of 28 items, preceded by the phrase "Why are you studying?" and distributed in seven subscales, five of them with four items and the remaining two with three: amotivation, external regulation, introjected regulation, identified regulation, motivation intrinsic toward knowledge, intrinsic motivation toward accomplishment and intrinsic motivation toward stimulating experiences. Responses were scored according to a seven-point Likert-type scale, from 1 (does not correspond at all) to 7 (fully corresponds). Reliability values were: $a=.65$ (amotivation) $a=.69$ (external regulation), $a=.74$ (introjected regulation), $a=.66$ (identified regulation) and $a=.90$ (intrinsic motivation). The SDI (Selfdetermination index) was calculated to check the results [(intrinsic motivation*2) + (identified regulation + introjected regulation)/2 - external regulation - (amotivation*2)].

2. Psychological needs satisfaction were measure using the questionnaire: Basic Psychological Needs in Exercise Scale (BPNES) (Moreno-Murcia et al., 2008). Participants answered on a Likert-type scale from 1 (Totally disagree) to 5 (Totally agree) composed of 12 items. Reliability values were: $\alpha=.65$ (autonomy) $\alpha=$ .45 (competence), $a=.53$ (relatedness). All variables were analysed using the Psychological Mediator Index (PMI) with a value of $a=.69$.

3. Personal and social responsibility was evaluated by using the questionnaire: Personal and Social Responsibility Questionnaire (PSRQ) (Escartí et al., 2011). Participants responded on a Likert-type scale from 1 (Totally disagree) to 6 (Totally agree) composed by 14 items. Questionnaire was presented along with the following statement: "It is normal to behave well at times and badly at other times. We are interested in finding out how you normally behave in physical education classes. There are no correct or incorrect answers. Please answer the following questions choosing the option which bests represents your behaviour". Reliability for social responsibility was $\alpha=.77$ and for personal responsibility was .68 .

4. Predisposition to PA was evaluate through the Scale of Intention to Be Physically Active (IBPA) (AriasEstero et al., 2013). Participants responded to a Liker-type scale from 1(Totally disagree) to 6 (Totally agree) composed by 5 items about predisposition to PA. Questionnaire was presented along with the following statement: "Regarding to your intention of practice physical activity...". The value of reliability for social responsibility was $\alpha=.58$, after deleting item 1 because reliability was .48 .

5. PA levels were quantified through the use of 68 accelerometers Actigraph wGT3X-BT with triaxial measurement of acceleration (Cordero-Aguilar et al., 2014). Results were given in "Counts" which are the sum of the absolute values of the acceleration change (Calahorro-Cañadas et al., 2015). All the accelerometers were loaded and put in date and time, programmed to record from 09:00 a.m. to 22:00 p.m., 
with the frequency of data collection at $60 \mathrm{~Hz}$. For the analysis of activity time measured by the accelerometer, the cut points proposed by Evenson et al. (2008) in children and young people and Moderate and Vigorous Activity (MVPA) was selected. MVPA is subsequently the sum of moderate and vigorous PA. Different moments were evaluated through the week to objectively measure PA levels. These moments were: during the complete week (e.g.: MVPA WK), during curricular hours (from 09:00 a.m. to 15:00 p.m.; e.g.: Sedentary $\mathrm{SCH}$ ), during extracurricular hours (from 15:00 to 22:00 pm; e.g.: Sedentary EX), during PE sessions (e.g.: MVPA PE), during the time of playtime at school (e.g.: Sedentary PT) and during the weekend (from 09:00 a.m. to 22:00 p.m. in Saturday and Sunday, e.g.: MVPA WKND).

\section{Procedure}

Four different and consecutive weeks were needed to accomplish a complete evaluation of the sample for this study. In one hand, questionnaires were given altogether to students, under permission of parents and schools, for them to fill along one of the hours of PE. On the other hand, students had to wear during a complete week an accelerometer on their right hip (Calahorro-Cañada et al., 2015). Precise instructions to families and students were given in order to correctly wear this device: not to be wear during the night or during aquatics activities, not to be share with other students or people outside the study, must be carry along a normal day during a week (also in the weekend), extracurricular PA was controlled by a personal diary.

To perform the present study, authors counted with a positive certificate issued by the Ethics Committee of the University of Murcia with number: ID/ 2637/2019.

\section{Statistical analysis}

Firstly, collected data regarding to sociodemographic and questionnaires was transferred and organised to Excel. Then a copy this data was exported to IBM SPSS software (23.0) for statistical analysis.

Secondly, collected data through accelerometers was managed with software Actilife 5.0. To analyse students' PA levels, the accelerometer had to be wore during a minimum period of 3 days during the week and 1 day at the weekend.

After that, descriptive values were performed (mean, standard deviation, asymmetry and kurtosis). Asymmetry and kurtosis values were $<3$ and $<10$ respectively being considered as good values for the study. Furthermore, Cronbach's Alpha was analysed with good values for all scales, positioned above .70, and for scales with few items is above .50 (Perry et al., 2004) except for competence. On the other hand, Kolmogorov-Smirnov and Shapiro-Wilk tests were performed for all the variables, showing a non-normal distribution for the most part of variables, Levene test and the box-diagrams confirmed this. For that, we used nonparametric tests for independent samples using $\mathrm{U}$ de Mann-Whitney test to check the relation between variables and Tau-B de Kendall to show possible correlation between Physical Activity Intention Scale and the accelerometery values. Finally, due to the small size sample we use the effect size of Cohen (1988) values less than 0.2 are considered to indicate an effect of small size, 0.5 of medium magnitude, and 0.8 indicates an effect of high magnitude.

\section{RESULTS}

\section{Descriptive results}

In Table 1, we can see the descriptive values of all variables. None of the variables had a high asymmetry or kurtosis value, considering like adequate to use it. The higher values were in External regulation ( $M=6.00$, $\mathrm{SD}=0.97)$ and the lower value was in amotivation $(M=1.79, \mathrm{SD}=1.21)$. 
Table 1. Descriptive analysis of psychological variables.

\begin{tabular}{lccccc}
\hline & M & SD & A & K & Range \\
\hline IPA & 4.45 & 0.54 & -0.789 & -0.495 & $1-5$ \\
Intrinsic Motivation & 5.70 & 0.96 & -0.795 & -0.066 & $1-7$ \\
Identified Regulation & 5.83 & 1.05 & -0.972 & 0.392 & $1-7$ \\
Introjected Regulation & 5.78 & 1.18 & -1.049 & 0.616 & $1-7$ \\
External Regulation & 6.00 & 0.97 & -1.224 & 1.081 & $1-7$ \\
Amotivation & 1.79 & 1.21 & 1.887 & 3.600 & $1-7$ \\
Autonomy & 3.93 & 0.72 & -0.393 & -0.601 & $1-7$ \\
Competition & 4.24 & 0.54 & -0.439 & -0.491 & $1-7$ \\
Relatedness & 4.46 & 0.55 & -1.266 & 0.917 & $1-5$ \\
Personal responsibility & 5.45 & 0.49 & -1.657 & 3.943 & $1-6$ \\
Social responsibility & 5.38 & 0.60 & -1.466 & 2.906 & $1-6$ \\
SDI & 3.81 & 1.81 & -1.371 & 2.105 & $/$ \\
PMI & 4.21 & 0.45 & -0.215 & -0.614 & $1-5$ \\
\hline
\end{tabular}

Legend: IPA = Intention to be Physically Active; $M=$ Mean, $S T$ = Standard Deviation; $A=$ Asymmetry; $K=$ Kurtosis; $S D I=$ Selfdetermination Index; PMI = Psychological Mediator Index.

On the other hand, correlations between the different indexes (SDI and PMI), responsibility, PA intention and PA are in Table 2. In this sense, most part of the correlations were positive except between sedentarism with moderate-vigorous PA in PE and personal responsibility. On the other hand, PMI, SDI, social responsibility and personal responsibility had a high correlation among them.

Table 2. Correlations between responsibility, motivation, psychological needs satisfaction and physical activity.

\begin{tabular}{lllllllll}
\hline & $\mathbf{2}$ & $\mathbf{3}$ & $\mathbf{4}$ & $\mathbf{5}$ & $\mathbf{6}$ & $\mathbf{7}$ & $\mathbf{8}$ & $\mathbf{9}$ \\
\hline 1 MVPA WK & $.276^{*}$ & .117 & .141 & .200 & -.153 & -.145 & -.197 & .055 \\
2 Sedentary WK & & $-.248^{*}$ & $.407^{* *}$ & -.134 & -.237 & -.211 & .122 & -.144 \\
3 MVPA PE & & & -.128 & $.284^{*}$ & .053 & -.050 & .166 & .118 \\
4 Sedentary PE & & & & -.209 & -.194 & $-.245^{*}$ & -.186 & -.104 \\
5 IPA & & & & & .221 & .086 & -.022 & .235 \\
6 Personal responsibility & & & & & & $.621^{* *}$ & $.303^{*}$ & $.576^{* *}$ \\
7 Social responsibility & & & & & & & $.308^{*}$ & $.546^{* *}$ \\
8 SDI & & & & & & & & $.362^{* *}$ \\
9 PMI & & & & & & &
\end{tabular}

Legend: $W K=$ Week; $P E=$ Physical Education; IPA = Intention to be Physically Active; MVPA = Moderate-vigorous physical activity; $S D I=$ Self-determination Index; $P M I=$ Psychological Mediator Index; $M=$ Mean; $S D=$ Standard Deviation; ${ }^{*} p<.05 ;{ }^{* *} p$ $<.01$.

\section{Psychological differences between gender}

On the other hand, in Table 3 we can see the differences between boys and girls. In this sense, girls showed higher values with significant differences $(p<.001)$ in social and personal responsibility, and in those cases without significant differences, a moderated effect in SDI (dif $=.73$ ), PNI (dif $=.17$ ) and autonomy psychological need $(\mathrm{dif}=.28)$.

Finally, in Table 4 we can see the different according to PA. According to gender, boys had higher values in all variables that shows statistical differences. Specifically, in sedentary total time (dif $=680.53)$, moderate 
total time (dif $=28.12$ ), sedentary school time (dif $=126.19)$, moderate time at playtime $(2.33)$ moderate in extracurricular time (dif $=16.12$ ) and MVPA in extracurricular time $($ dif $=30.69)$.

Table 3. Differences according to gender between psychological variables and intention to be physically active.

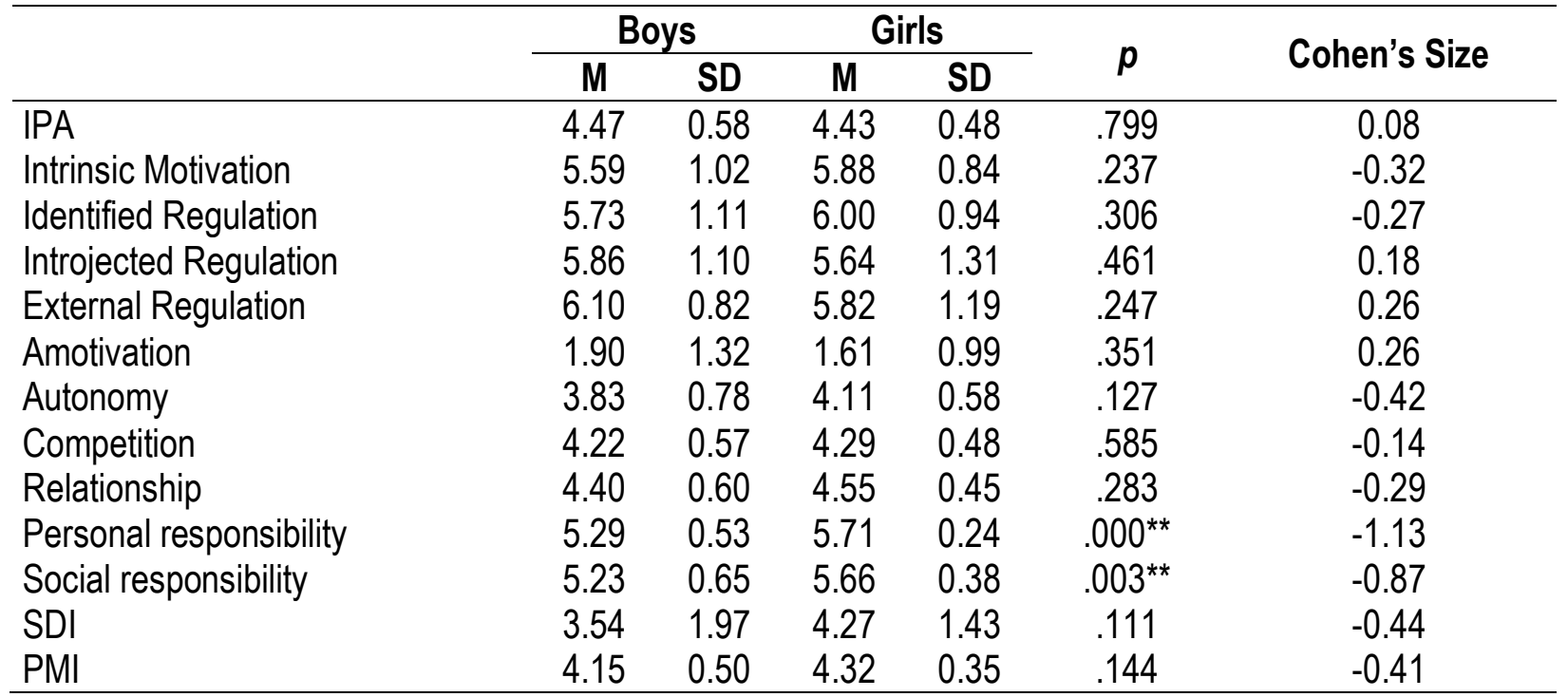

Legend: IPA = Physical Activity Intention; SDI = Self-determination Index; $P M I=$ Psychological Mediator Index; $M=$ Mean; $S D=$ Standard Deviation; ${ }^{* *} p<.01$.

Table 4. Differences according to PA levels with accelerometer.

\begin{tabular}{lcccccc}
\hline & \multicolumn{2}{c}{ Boys } & \multicolumn{2}{c}{ Girls } & \multirow{2}{*}{ Cohen's Size } \\
\cline { 2 - 5 } & $\mathbf{M}$ & SD & $\mathbf{M}$ & SD & & \\
\hline Sedentary WK & 5256.52 & 1375.67 & 4575.99 & 746.25 & $.026^{*}$ & 0.57 \\
Light WK & 539.33 & 215.93 & 471.97 & 133.55 & .164 & 0.35 \\
Moderate WK & 147.69 & 57.81 & 119.57 & 38.32 & $.034^{*}$ & 0.55 \\
Vigorous WK & 131.49 & 63.48 & 110.99 & 45.11 & .161 & 0.36 \\
MVPA WK & 279.18 & 110.65 & 230.56 & 77.43 & .057 & 0.49 \\
Sedentary SCH & 973.94 & 237.87 & 847.75 & 167.35 & $.023^{*}$ & 0.59 \\
Light SCH & 135.51 & 55.23 & 118.46 & 36.56 & .173 & 0.35 \\
Moderate SCH & 34.82 & 12.12 & 30.10 & 10.39 & .108 & 0.41 \\
Vigorous SCH & 31.86 & 14.09 & 28.12 & 12.71 & .278 & 0.27 \\
MVPA SCH & 66.69 & 25.17 & 58.22 & 22.12 & .167 & 0.35 \\
Sedentary PT & 56.65 & 24.61 & 52.15 & 18.69 & .432 & 0.20 \\
Light PT & 29.40 & 13.78 & 25.06 & 8.17 & .157 & 0.36 \\
Moderate PT & 10.68 & 5.02 & 8.35 & 3.94 & $.049^{*}$ & 0.50 \\
Vigorous PT & 12.10 & 6.81 & 9.24 & 6.54 & .095 & 0.43 \\
MVPA PT & 22.79 & 11.15 & 17.59 & 9.98 & .059 & 0.48 \\
Sedentary PE & 83.44 & 34.01 & 79.81 & 39.25 & .690 & 0.10 \\
Light PE & 11.81 & 8.63 & 9.60 & 5.96 & .263 & 0.28 \\
Moderate PE & 3.44 & 2.83 & 2.41 & 1.73 & .105 & 0.41 \\
Vigorous PE & 4.57 & 4.86 & 2.97 & 3.90 & .165 & 0.35 \\
MVPA PE & 8.01 & 7.22 & 5.38 & 5.27 & .117 & 0.40 \\
Sedentary EX & 1282.09 & 214.18 & 1212.44 & 240.72 & .221 & 0.31 \\
\hline
\end{tabular}




$\begin{array}{lcccccc}\text { Light EX } & 229.93 & 110.91 & 189.28 & 56.76 & .093 & 0.43 \\ \text { Moderate EX } & 67.38 & 34.04 & 51.26 & 19.37 & .034^{*} & 0.55 \\ \text { Vigorous EX } & 64.69 & 36.02 & 50.13 & 23.65 & .076 & 0.45 \\ \text { MVPA EX } & 132.08 & 63.59 & 101.39 & 39.71 & .033^{*} & 0.55 \\ \text { Sedentary WKND } & 1137.79 & 329.66 & 1117.78 & 351.80 & .815 & 0.06 \\ \text { Light WKND } & 122.45 & 73.89 & 121.04 & 63.84 & .937 & 0.02 \\ \text { Moderate WKND } & 34.36 & 23.11 & 26.74 & 14.63 & .143 & 0.37 \\ \text { Vigorous WKND } & 27.32 & 22.91 & 24.43 & 17.45 & .587 & 0.14 \\ \text { MVPA WKND } & 61.64 & 42.06 & 51.16 & 29.94 & .279 & 0.27\end{array}$

Legend: $M V P A=$ Moderate-vigorous physical activity; $M=$ Mean; $S D=$ Standard Deviation; ${ }^{*} p<.05 ; W K=$ Week; $S C H=$ School; $P T=$ Playtime; $P E=$ Physical Education; $E X=$ Extracurricular; $W K N D=$ Weekend .

\section{DISCUSSION}

The aim of this study was firstly, to compare gender differences in PA levels, motivation, basic psychological needs, and responsibility in elementary school students and, secondly, to examine whether motivation, psychological needs, responsibility, and IBPA had correlations with PA levels.

With respect to the first objective, the results show significant differences in the social and personal responsibility variables in favour of the female group, as well as a moderate effect on SDI, PMI and autonomy. These results are in line with the study by Manzano-Sánchez et al. (2019), where the values of social and personal responsibility in adolescent females were significantly higher than in male students. In addition, it is observed that girls had higher values than boys in the variables of motivation and basic psychological needs satisfaction, such as autonomy, with a moderate effect, as similarly observed in the studies by Amado et al. (2016) and Manzano-Sánchez et al. (2019)..

However, the results of the present study do not reflect significant differences in the IBPA between both genders, which is in contrast to the results obtained by Gómez-López et al. (2019) in their study with a sample of handball players, in which they found significant differences in favour of girls. In this research, slightly higher values are found in boys, in line with the study by Munuera-Ortuño et al. (2018) conducted with a sample of high school students, where the results reflect that boys have a greater IBPA than girls.

On the other hand, the results referring to PA levels show that male students had higher values than female students, finding significant differences between both genders in total moderate PA time, moderate play time, moderate intensity in extracurricular time, and MVPA in extracurricular time. Other studies that used accelerometry to measure PA level in high school students, such as Manzano-Sánchez and ValeroValenzuela (2018), found no significant gender differences, but higher values in active steps during the week and weekend in favour of adolescent males. In the study by Martínez-Baena, et al. (2016), where accelerometers were also used, the results showed significant differences in PA levels according to gender, with such values being higher in men. Although the values of the present study show higher and statistically significant values in men, significant differences were also found in total sedentary time and sedentary school time in favour of this gender. Therefore, these results do not follow the line of those found in the study by Beltrán-Carrillo et al. (2017), which reflect that sedentary time in school, extracurricular, and total time was statistically higher in female students.

Regarding the second objective, which was to examine whether motivation, psychological needs satisfaction, responsibility, and predisposition to be physically active have correlations with PA levels, the results show 
that MVPA has a significantly positive relationship with IBPA, in line with the results of the study by Fernandez-Rio et al. (2018), which indicated that the intention to engage in PA has positive associations with the practice of PA by adolescents. On the other hand, it is observed that sedentarism has a significantly negative relationship with the MVPA in PE and with social responsibility. These results follow the line of Gómez-Mármol et al. (2017), whose research reflects that a greater number of hours dedicated to sedentary activities means a reduction in personal and social responsibilities, as well as in the level of PA performed.

The main limitation of this study was that there was a scarce sample in a very wide sample universe, since the use of accelerometry caused that some of the participants had to be excluded because they did not meet the inclusion criteria, as it happened in other studies such as Manzano-Sánchez and Valero-Valenzuela (2018). On the other hand, the scale of competence had a low reliability value.

\section{CONCLUSIONS}

In conclusion, it can be said that there were significant differences in the variables under study according to gender. On the one hand, girls had higher adaptive values of motivation, responsibility and satisfaction of basic psychological needs than boys. On the other hand, boys had higher values with respect to PA and sedentarism.

In relation to the second of the objectives, the MVPA is positively associated with the IBPA, while the sedentary lifestyle has a negative relationship with the level of PA and social responsibility.

For future studies, it is recommended to measure the PA level through accelerometers, since the data obtained with this instrument show the objective PA level that students practice at each moment of the day. In addition, during PE classes a greater responsibility on the part of the students should be encouraged through active methodologies, because in this way these levels of PA and the motivation directly towards the practice of PA will be increased and, therefore, the health and quality of life of the students will be favoured.

\section{REFERENCES}

Amado, D., Sánchez-Miguel, P. A., González-Ponce, I., Pulido-González, J. J., \& Del Villar, F. (2016). Motivation towards dance within physical education according to teaching technique and gender. $S$ Afr J Res Sport Ph, 38(2), 1-16.

Arias-Estero, J. L., Castejón-Oliva, F. J., \& Yuste-Lucas, J. L. (2013). Propiedades psicométricas de la escala de intencionalidad de ser físicamente activo en educación primaria. Rev Educ, 362, 485-505. https://doi.org/10.4438/1988-592X-RE-2013-362-239

Beltrán-Carrillo, V. J., Sierra, A. C., Jiménez-Loais, A., González-Cutre, D., Martínez-Galindo, C., \& Cervelló, E. (2017). Diferencias según género en el tiempo empleado por adolescentes en actividad sedentaria y actividad física en diferentes segmentos horarios del día. Retos, 31, 3-7. https://doi.org/10.47197/retos.v0i31.36207

Bull, F.C., Al-Ansari, S.S., Biddle, S., Borodulin, K., Buman, M.P., Cardon, G., Carty, C., Chaput, J.P., Chastin, S., Chou, R., Dempsey, P.C., DiPrietro, L., Ekelund, U., Firth, J., Friedenreich, C.M., García, L., Gichu, M., Jago, R., Katzmarzyk, P.T., ... Willumsen, J.F. (2020). World Heath Organization 2020 guidelines on phpysical activity and sedentary behaviour. Brit J Sport Med, 54(24), 1451-1462. https://doi.org/10.1136/bjsports-2020-102955 
Calahorro-Cañada, F., Torres-Luque, G., López-Fernández, I., Santos-Lozano, A., Garatachea, N., \& Álvarez-Carnero, E. (2015). Actividad física y acelerometría; orientaciones metodológicas, recomendaciones y patrones. Nutr Hosp, 31(1), 115-125. https://doi.org/10.3305/nh.2015.31.1.7450

Cangas, A., Gázquez, J., Pérez-Fuentes, M. C., Padilla, D., \& Miras, F. (2007). Evaluación de la violencia escolar y su afectación personal en una muestra de estudiantes europeos. Psicothema, 19(1), 114119.

Carranza, M., \& Mora, J. (2003). Educación física y valores: educando en un mundo complejo. Grao.

Cheng, L. A., Mendonça, G., Lucena, J. M. S., Rech, C. R., \& Farias, J. C. (2020). Is the association between sociodemographic variables and physical activity levels in adolescents mediated by social support and self-efficacy? J Pediat-Brazil, 96(1), 46-52. https://doi.org/10.1016/j.jped.2018.08.003

Cordero-Aguilar, M. J., Sánchez-López, A. M., Guisado-Barrilao, R., Rodriguez-Blanque, B. R., NoackSegovia, J., \& Cano-Pozo, M. D. (2014). Descripción del acelerómetro como método para valorar la actividad física en los diferentes periodos de la vida; revisión sistemática. Nutr Hosp, 29(6), 1250 1261. https://doi.org/10.3305/nh.2014.29.6.7410

Courel-Ibáñez, J., Sánchez-Alcaraz, B. J., Gómez-Mármol, A., Valero-Valenzuela, A. \& Moreno-Murcia, J. A. (2019). The moderating role of sportsmanship and violent attitudes on social and personal responsibility in adolescents. A clustering-classification approach. Plos One, 14(2). https://doi.org/10.1371/journal.pone.0211933

Deci, E. L., \& Ryan, R. (2012). Self-determination theory. In V. L. P.A.M., A. W. Kruglanski, \& E. T. Higgins (Eds.), Handbook of theories of social psychology (pp. 416-436). Sage Publications Ltd. https://doi.org/10.4135/9781446249215.n21

Di Cesare, M., Sorić, M., Bovet, P., Miranda, J. J., Bhutta, Z., Stevens, G. A., Laxmaiah, A., Kengne, A. P., \& Bentham, J. (2019). The epidemiological burden of obesity in childhood: A worldwide epidemic requiring urgent action. BMC Med, 17(212). https://doi.org/10.1186/s12916-019-1449-8

Escartí, A., Gutiérrez, M., \& Pascual, C. (2011). Propiedades psicométricas de la versión española del Cuestionario de Responsabilidad Personal y Social en contextos de educación física. Rev Psicol Deporte, 20(1), 119-130.

Evenson, K. R., Catellier, D. J., Gill, K., Ondrak, K. S., \& McMurray, R. G. (2008). Calibration of two objective measures of physical activity for children. J Sport Sci, 26(14), 1557-1565. https://doi.org/10.1080/02640410802334196

Fernandez-Rio, J., Cecchini, J.A., Mendez-Gimenez, A., \& Mendez-Alonso, D. (2018). Adolescents' competence metaperceptions and self-perceptions, motivation, intention to be physically active and physical activity. Cuadernos de Psicología del Deporte, 18(1), 75-80.

Gómez-López, M., Merino-Barrero, J. A., Valero-Valenzuela, A. \& Manzano-Sánchez, D. (2019). A cluster analysis of high-performance handball players' perceived motivational climate: Implications on motivation, implicit beliefs of ability and intention to be physically active. Int J Sports Sci Coa, 14(4), 541-551. https://doi.org/10.1177/1747954119861855

Gómez-Mármol, A., Sánchez-Alcaraz, B.J., De la Cruz, E., Valero-Valenzuela, A. \& González-Víllora, S. (2017). Personal and social responsibility development through sport participation in youth scholars. Journal of Physical Education and Sport, 17(2), 775-782. https://doi.org/10.7752/jpes.2017.02118

Hellison, D. (2011). Teaching responsibility through physical activity. Human Kinetics.

Kalajas-Tilga, H., Koka, A., Hein, V., Tilga, H., \& Raudsepp, L. (2020). Motivational processes in physical education and objectively measured physical activity among adolescents. J Sport Health Sci, 9(5), 462-471. https://doi.org/ 10.1016/j.jshs.2019.06.001

Manzano-Sánchez, D., \& Valero-Valenzuela, A. (2018). Differences between students according to physical activity and their motivation, basic psychological needs and responsibility. Journal of Human Sport and Exercise, 13(Proc2), 221-230. https://doi.org/10.14198/ihse.2018.13.Proc2.06 
Manzano-Sánchez, D., Valero-Valenzuela, A., Conde-Sánchez, A., \& Chen, M. Y. (2019). Applying the personal and social responsibility model-based program: Differences according to gender between basic psychological needs, motivation, life satisfaction and intention to be physically active. International journal of environmental research and public health, 16(13), 2326. https://doi.org/10.3390/ijerph16132326

Martínez-Baena, A., Mayorga-Vega, D., \& Viciana, J. (2016). Relación de los niveles de actividad física con el género y el perfil de riesgo cardiovascular en adolescentes granadinos. Implicaciones didácticas para la educación física. Profesorado. Revista de Currículum y Formación de Profesorado, 20(1), 265-285.

Montero, I., \& León, O. G. (2007). A guide for naming research studies in Psychology. Int J Clin Hlth Psyc, 7(3), 847-862.

Moreno-Murcia, J. A., González-Cutre Coll, D., Chillón-Garzón, M., \& Parra-Rojas, N. (2008). Adaptación a la educación física de la escala de las necesidades psicológicas básicas en el ejercicio. Rev Mex Psicol, 25(2), 295-303.

Munuera-Ortuño, J. M., Gómez-López, M., Granero-Gallegos, A., \& Sánchez-Alcaraz Martínez, B. J. (2018). Miedo al fallo de los estudiantes y la relación con la intención de ser físicamente activo e importancia de la Educación Física en Educación Secundaria. Estudios Pedagógicos, 44(1), 279291.

Mura, G., Rocha, B. F., Helmich, I., Budde, H., Machado, S., Wegner, M., Egidio-Nardi, A., Arias-Carrión, O., Vellante, M., Baum, A., Guicciardi, M., Patten, S. B., \& Giovanni-Carta, M. (2015). Physical activity interventions in schools for improving lifestyle in European countries. Clinical Practice \& Epidemiology in Mental Health, 11(1), 77-101. https://doi.org/10.2174/1745017901511010077

Núñez-Alonso, E., Martín-Albo, J., \& Navarro-lzquierdo, J. G. (2005). Validación de la versión española de la échelle de motivation en éducation. Psicothema, 17(2), 344-349.

Perry, R. H., Charlotte, B., Isabella, M., \& Bob, C. (2004). SPSS explained. Routledge.

Ryan, R. M., \& Deci, E. L. (2017). Self-determination theory: Basic psychological needs in motivation, development, and wellness. Guilford Publications. https://doi.org/10.1521/978.14625/28806

Sánchez-Alcaraz, B., Courel-Ibáñez, J., Sánchez-Ramírez, C., Valero-Valenzuela, A., \& Gómez-Mármol, A. (2019). Personal and social responsibility model through sports: A bibliographic review. Retos, 40(9), 755-762. https://doi.org/10.47197/retos.v37i37.67890

Standage, M., Gillison, F. B., Ntoumanis, N., \& Treasure, D. C. (2012). Predicting Students' Physical Activity and Health-Related Well-Being: A Prospective Cross-Domain Investigation of Motivation Across School Physical Education and Exercise Settings. J Sport Exercise Psy, 34(1), 37-60. https://doi.org/10.1123/isep.34.1.37

Van Hecke, L., Loyen, A., Verloigne, M., van der Ploeg, H. P., Lakerveld, J., Brug, J., De Bourdeaudhuij, I., Ekelund, U., Donnelly, A., Hendriksen, I., \& Deforche, B. (2016). Variation in population levels of physical activity in European children and adolescents according to cross-European studies: A systematic literature review within DEDIPAC. Int $J$ Behav Nutr Phy, 13(1). https://doi.org/10.1186/s12966-016-0396-4

Wang, L. (2017). Using the self-determination theory to understand Chinese adolescent leisure-time physical activity. Eur J Sport Sci, 17(4), 453-461. https://doi.org/10.1080/17461391.2016.1276968

\section{(9)}

This work is licensed under a Attribution-NonCommercial-NoDerivatives 4.0 International (CC BY-NC-ND 4.0). 